\title{
Ischemic Stroke in Infants and Children: Practical Management in Emergency
}

\author{
Sara Ciccone, Michela Cappella, and Caterina Borgna-Pignatti \\ Department of Clinical and Experimental Medicine-Pediatrics, University of Ferrara, 44121 Ferrara, Italy \\ Correspondence should be addressed to Sara Ciccone, saraciccone.unife@gmail.com
}

Received 23 September 2010; Revised 27 April 2011; Accepted 2 May 2011

Academic Editor: Halvor Naess

Copyright () 2011 Sara Ciccone et al. This is an open access article distributed under the Creative Commons Attribution License, which permits unrestricted use, distribution, and reproduction in any medium, provided the original work is properly cited.

Stroke is a rare disease in children, with an estimated incidence 13/100000 and a significant impact on morbidity and mortality. Clinical presentation and risk factors, present in almost half of pediatric patients, are not the same as in adults. The diagnosis of stroke in children is often delayed because signs and symptoms can be subtle and nonspecific. History and clinical examination should exclude underlying diseases or predisposing factors. Neuroimaging is crucial in defining diagnosis. Other tests might be necessary, according to the clinical picture. We present here the most recent practical directions on how to diagnose and manage arterial stroke in children, according to different international guidelines on the subject.

\section{Introduction}

The World Health Organization (WHO) defines stroke as "a clinical syndrome of rapidly developing focal or global disturbance of brain function lasting $>24$ hours or leading to death with no obvious nonvascular cause" [1]. This definition should be integrated by a reference to neuroimaging, at present considered essential to define the neurovascular origin of symptoms. A modern definition could be "a clinical syndrome characterized by (1) a neurological deficit related to the perfusion territory of a cerebral artery and (2) neuroradiological evidence of an ischemic lesion" $[2,3]$.

Transient ischemic attacks (TIAs) are defined as "a sudden, focal neurologic deficit that lasts for less than 24 hours, of presumed vascular origin, confined to an area of the brain or eye perfused by a specific artery" [4]. In childhood, on the contrary, even in the presence of transient symptoms, imaging often shows a cerebral infarction [5].

Strokes are classically divided in primarily ischemic or hemorrhagic. While adult strokes are prevalently ischemic ( $80 \%)$ and due to atherosclerosis, in childhood up to $45 \%$ of strokes are hemorrhagic and are associated with a wide spectrum of risk factors [6].

The estimated incidence of ischemic stroke in children older than 28 days of life is variable [7-9] but, according to a large prospective, population study, it averages $13 / 100.000$ for all strokes, 7.9/100.000 for ischemic strokes, and 5.1 for hemorrhagic strokes [8]. Approximately 20\% of children die after an ischemic stroke while more than $50 \%$ of those surviving present neurological sequelae, most commonly hemiparesis $[7,9]$. The cumulative stroke recurrence rate has been reported to be $15 \%$ at 1 year, and $19 \%$ at 5 years [10], and up to $41 \%$ at 5 years [11].

A risk factor is present in almost half of the children at the time of stroke [12] (Table 1). Common risk factors in childhood are congenital heart disease, sickle cell disease, infections, and various prothrombotic conditions [13-15]. The most common cause of stroke in children is probably heart disease, detected in 19\% of children with arterial thrombosis (Canadian Pediatric Ischemic Stroke Registry) [16]. Recent studies underline the importance of infection: it seems that at least a third of cases of childhood stroke occur in such a context. A fifth of the children with ischemic infarction of unknown origin has a history of prior chickenpox [16-18].

In about $80 \%$ of children with arterial stroke, arterial imaging is abnormal [12].

The purpose of this paper is to provide practical upto-date directions on how to diagnose and manage arterial stroke in children (1 month-18 years), in an emergency department. Neonatal stroke is not included because of its peculiar characteristics. 
TABLE 1: Risk factors for pediatric stroke.

Congenital heart disease

Ventricular/atrial septal defect

Patent ductus arteriosus

Aortic/mitral stenosis

Coarctation

Cardiac rhabdomyoma

Complex congenital heart defects

Acquired heart disease

Rheumatic heart disease

Prosthetic heart valve

Endocarditis

Cardiomyopathy

Myocarditis

Atrial myxoma

Arrhythmia

Systemic vascular disease

Systemic hypertension

Volume depletion or systemic hypotension

Hypernatremia

Superior vena cava syndrome

Diabetes

Vasculitis

Meningitis

Systemic infection

Systemic lupus erythematosus

Polyarteritis nodosa

Granulomatous angiitis

Takayasu's arteritis

Rheumatoid arthritis

Dermatomyositis

Inflammatory bowel disease

Drug abuse (cocaine, amphetamines)

Hemolytic-uremic syndrome

Vasculopathies

Ehlers-Danlos syndrome

Homocystinuria

Moyamoya syndrome

Fabry's disease

Malignant atrophic papulosis

Pseudoxanthoma elasticurn

NADH-CoQ reductase deficiency

Vasospastic disorders

Migraine

Ergot poisoning

Vasospasm with subarachnoid hemorrhage

Hematologic disorders and coagulopathies

Hemoglobinopathies (sickle cell anemia, sickle

cell-hemoglobin C, sickle-thalassemia)

Immune thrombocytopenic purpura

Thrombotic thrombocytopenic purpura
TABLE 1: Continued.

Hematologic disorders and coagulopathies

Thrombocytosis

Polycythemia

Disseminated intravascular coagulation

Leukemia or other neoplasms

Congenital coagulation defects

Oral contraceptive use

Antithrombin III deficiency

Protein S deficiency

Protein C deficiency

Congenital serum C2 deficiency

Liver dysfunction with coagulation defect

Vitamin K deficiency

Lupus anticoagulant

Anticardiolipin antibodies

Structural anomalies of the cerebrovascular system

Arterial fibromuscular dysplasia

Agenesis or hypoplasia of the internal carotid or

vertebral arteries

Arteriovenous malformation

Hereditary hemorrhagic telangiectasia

Sturge-Weber syndrome

Intracranial aneurysm

Trauma

Child abuse

Fat or air embolism

Foreign body embolism

Carotid ligation

Vertebral occlusion following abrupt cervical rotation

Posttraumatic arterial dissection

Blunt cervical arterial trauma

Arteriography

Posttraumatic carotid cavernous fistula

Coagulation defect with minor trauma

Penetrating intracranial trauma

In preparing this work we followed the most recent guidelines on arterial stroke in childhood (Pediatric Stroke Working Group, 2004; American College of Chest Physicians, 2004; Italian Society of Pediatrics, 2007; American Stroke Association, 2008).

Additionally, a literature review was made, analyzing relevant articles on the subject, up to August, 2010 by searching Pubmed, EMBASE, Cochrane Library and in bibliographies of relevant articles. Search terms were "stroke," "emergency," "child," "childhood," "management."

\section{Diagnosis}

2.1. Clinical Presentation. The clinical presentation of stroke differs depending on age, involved artery, and cause $[19,20]$. 
TABLE 2: Clinical presentation of stroke depending on the involved artery.

\begin{tabular}{|c|c|}
\hline Vascular territory & Symptoms \\
\hline Internal carotid artery & Hemiparesis, aphasia, and hemianopsia \\
\hline Anterior cerebral artery & Hemiparesis, especially leg \\
\hline Middle cerebral artery & $\begin{array}{l}\text { Arm hemiparesis, hemianopsia, and } \\
\text { aphasia }\end{array}$ \\
\hline Posterior cerebral artery & $\begin{array}{l}\text { Hemianopsia, ataxia, hemiparesis, and } \\
\text { dizziness }\end{array}$ \\
\hline Basilar artery & $\begin{array}{l}\text { Breath, sensory or balance disturbances, } \\
\text { ataxia, nystagmus, opisthotonus, } \\
\text { tremor, and vomiting }\end{array}$ \\
\hline Cerebellar artery & $\begin{array}{l}\text { Sensory disturbances, headache, fever, } \\
\text { vomit, and cerebellar signs }\end{array}$ \\
\hline
\end{tabular}

While in infancy symptoms are usually aspecific, in older children, the most frequent presenting symptoms are focal neurologic deficits such as hemiplegia or a gross, focal motor deficit [21].

Symptoms according to the involved artery are listed in Table 2. The vascular territory of the middle cerebral artery is the most frequently affected.

2.2. Differential Diagnosis. Diagnosis of stroke in children is often delayed because signs and symptoms can be subtle and nonspecific, such as mild single limb weakness, incoordination, and sensory disturbances, initially attributed to causes other than stroke [22].

In a child presenting with an acute neurologic deficit, before a diagnosis of ischemic stroke is made, other cerebrovascular diseases (hemorrhagic stroke, cerebral venous sinus thrombosis) need to be considered.

Frequent causes of acute hemiplegia are Todd's palsy, where focal seizures usually precede monoparesis or hemiplegia, and hemiplegic migraine, in which hemiplegia is preceded by visual or sensitive disorders and followed by headache. It is also necessary to exclude meningoencephalitis, generally associated with fever, headache and altered consciousness.

Acute neurologic deficits may be caused by tumors, central nervous system disorders including acute disseminated leukoencephalitis, cerebellitis, reversible posterior leukoencephalopathy, alternating hemiplegia, metabolic disorders, epilepsy, and psychogenic diseases [23].

2.3. Early Investigations (on Presentation). The first step to detect a stroke is including this option in the differential diagnosis of an acutely ill child. Early diagnosis allows prompt starting of appropriate therapy.

2.3.1. History. Clinical history should include ethnic origin, the presence of sickle cell disease or congenital heart disease, head or neck trauma (associated with intracranial hemorrhage and dissection), recent infection (especially chickenpox), vasculitis and blood disorders [19], as well as cerebrovascular diseases, coagulopathies, or immunologic disorders among first-degree relatives.
How and how rapidly symptoms develop is of major importance. Up to a third of children who have had a stroke have a history of recent events consistent with TIAs [24].

2.3.2. Physical Examination. A complete physical and neurologic examination, including monitoring of vital parameters, will identify neurologic damages and allow presumptive diagnosis of the brain vessel involved. Signs of systemic diseases that increase the risk of stroke should be looked for.

2.3.3. Imaging Studies. Non-contrast computed tomography (CT) can be performed promptly and quickly in emergency. It can adequately exclude hemorrhagic stroke or parenchymal abnormalities that produces a mass effect, and it may reveal a low-density lesion in arterial ischemic stroke and cerebral venous sinus thrombosis. However, CT is usually normal within the first 12 hours after the onset of symptoms [6]. It should be requested whenever magnetic resonance (MR) is not available [19].

$\mathrm{MR}$, in fact, is the "gold standard" imaging modality for the investigation of arterial ischemic stroke in infants and children [25] due to its greater sensitivity and specificity. MR is useful to differentiate stroke from "stroke mimics" but it is rarely available in emergency [26]. The diagnostic efficiency of MR can be further improved by perfusion techniques, that quantify relative cerebral blood flow, volume, and transit time by the use of bolus administration of gadolinium-based contrast material $[5,27,28]$.

MR with diffusion weighting is very useful in accurately identifying regions of early ischemia and infarction [26]. MR angiography is a noninvasive procedure that detects large vascular abnormalities [29], and it is as effective as cerebral angiography in identifying large ischemic lesions [30]. MR angiography is a reasonable alternative to conventional arteriography in most patients $[31,32]$. If the pattern of brain injury could be consistent with venous infarction, emergency vascular imaging should include MR venography. In fact, $10 \%$ of hemorrhagic strokes in children are secondary to cerebral venous sinus thrombosis [6].

Vascular imaging of the extracranial circulation, such as cervical MRA or Doppler ultrasound, should also be performed, particularly if the history is suggestive of a cervical arterial dissection.

2.3.4. Other Investigations. Complete blood cell count, iron studies, prothrombin time, partial thromboplastin time, sedimentation rate, and antinuclear antibodies could be useful [19].

2.4. Second-Line Investigations (after 48 Hours as Indicated). Once stroke has been diagnosed, several studies may be helpful for the ongoing evaluation and management of the patient.

Electrocardiogram and transthoracic or transesophageal echocardiogram are always necessary in all children with known or suspected congenital heart disease who have had a stroke $[20,33]$.

Echocardiography may be helpful to diagnose patent foramen ovale; this abnormality can be up to four times 
Flowchart:

ischemic stroke diagnosis in emergency

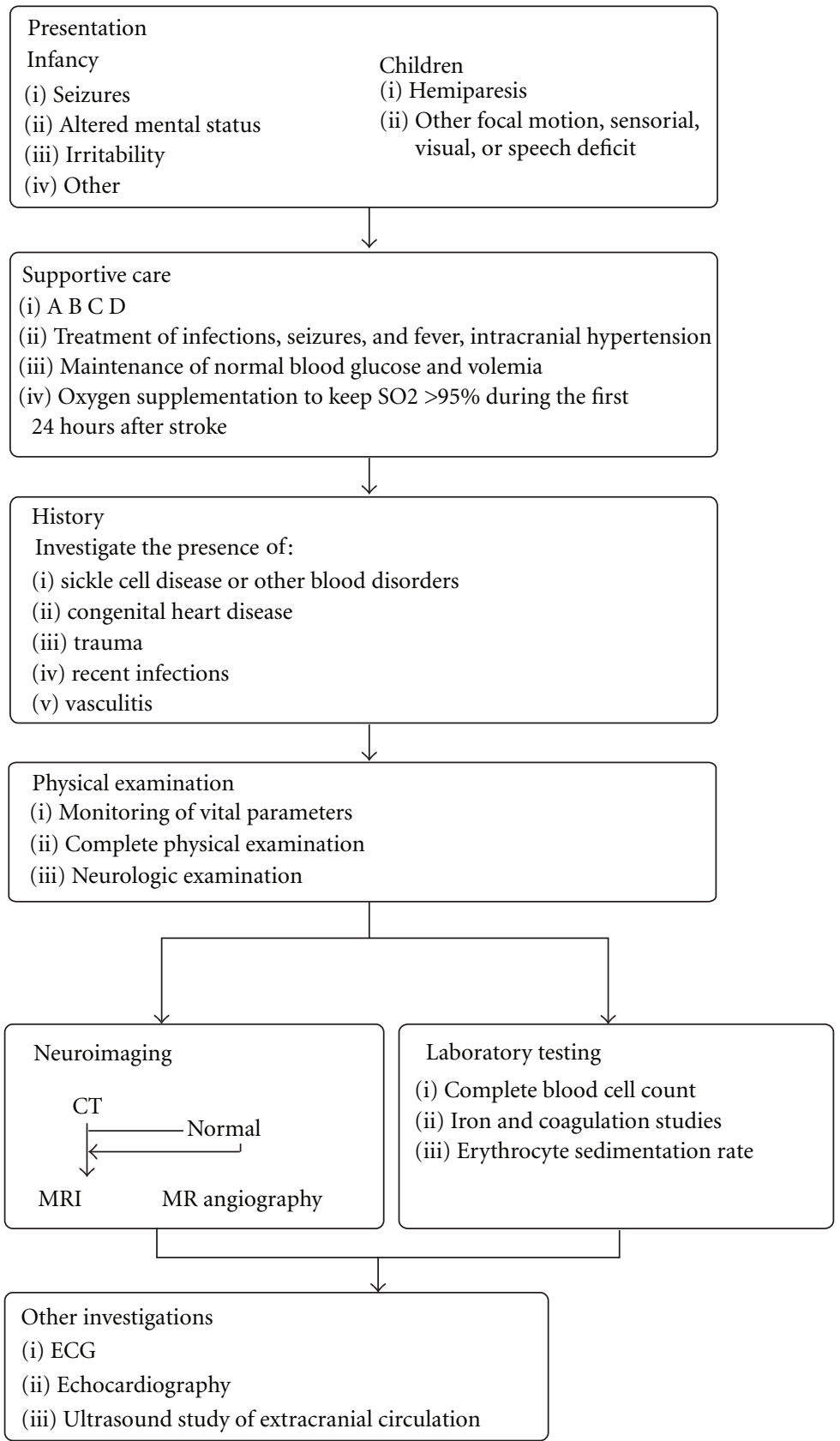

FIGURE 1: Flowchart: diagnosis of ischemic stroke in emergency.

greater in children with stroke with undetermined etiology than in the general population [34].

The diagnosis of some conditions, including extracranial arterial dissection, particularly involving the posterior circulation, and small-vessel vasculitis, is difficult using MR angiography alone. In these circumstances, catheter cerebral angiography is sometimes required. However, catheter cerebral angiography is an invasive procedure, not commonly performed in children, and it has similar diagnostic yield as
MR combined with MR venography and MR arteriography [6].

Conventional angiography can be necessary in order to identify moyamoya syndrome [19].

Hemoglobin electrophoresis and urine drug screening, particularly for sympathomimetics may be indicated. A full evaluation for thrombophilia is reasonable in all children with stroke. It should include evaluation of protein $\mathrm{C}$ and protein S deficiency, antithrombin III, heparin cofactor II, 
plasminogen, von Willebrand's antigen, factor VIII, factor XII, factor V Leiden, activated protein C resistance, prothrombin 20210 gene, serum homocysteine, methylenetetra-hydro-folate-reductase, lipoprotein (a), and antiphospholipid antibodies [35-37]. When indicated on the basis of clinical suspicion, more extensive diagnostic testing, such as cerebrospinal fluid analysis, lipid profile, Varicella-Zoster and human immunodeficiency virus, and screening for metabolic disorders might be performed. However, in the majority of cases, the results of these studies will not have an impact on emergency care [19]. We suggest a flow chart for diagnosis of ischemic stroke in emergency (see Figure 1).

\section{Management in Emergency}

Guidelines based on strong evidence for the acute care of childhood stroke do not exist, with the exception of sickle cell disease. Therefore, treatment recommendations for ischemic stroke in children are extrapolated from adult guidelines.

Children with early acute ischemic cerebral stroke need to be admitted to a clinical unit where continuous monitoring is possible. Only in selected cases treatment in intensive care units is needed $[38,39]$.

3.1. Supportive Care. The general approach in emergency includes simple measures such as maintenance of respiratory and cardiovascular functions, aggressive treatment of infection, seizures and fever, maintenance of normoglycemia and normovolemia $[20,40]$, and oxygen supplementation to keep $\mathrm{SaO}_{2}>95 \%$ during the first 24 hours after stroke [41]. Medical or surgical treatment of intracranial hypertension, when present, is important, because children have higher risk of tonsillar herniation due to cerebral edema. Hyperventilation is a short term solution that should be used for imminent herniation until a definitive therapy, such as decompressive neurosurgery, can be offered [40,42, 43].

3.2. Anticoagulant Therapy and Antiplatelet Agents. The choice between anticoagulant and antiplatelet agents is controversial and there are few data to guide this decision in children [44].

As anticoagulation therapy, both unfractionated heparin and low molecular weight heparin (LMWH) have been used in children with AIS. Current guidelines recommend anticoagulation in children with proven arterial dissection or cardioembolic stroke or during the diagnostic evaluation period, until a cardiac source or an arterial dissection has been excluded [42]. Heparin should be used in children thought to have a high risk of recurrence and a low risk of secondary hemorrhage $[5,45]$.

According to the international literature, $\mathrm{LMWH}$ at the dose of $1 \mathrm{mg} / \mathrm{kg}$ every 12 hours represents a safe initial therapy for ischemic stroke in infants and children. Hemorrhagic stroke needs to be excluded before starting treatment [4649]. Low molecular weight heparin offers several advantages over standard unfractionated heparin and oral anticoagulants: lower risk of heparin-induced thrombocytopenia, fewer drug interactions, fewer adverse effects on bone when given long term, and lower cost. Furthermore, LMWH is administered subcutaneously, and it demonstrates predictable age-dependent pharmacokinetics and less need for monitoring, thus reducing the need for multiple venipunctures [46]. Enoxaparin $(1 \mathrm{mg} / \mathrm{kg}$ subcutaneously for children more than 2 months of age, or $1.5 \mathrm{mg} / \mathrm{kg}$ for infant less than 2 months of age) is the most frequently used LMWH in children [47]. In children with cardiac embolism or vascular dissection, LMWH is administered for 3 to 6 months [50].

Concerning antiplatelets, even in absence of randomized clinical trials for the use of aspirin in the acute treatment of AIS in children, most experts agree that this drug use is reasonable for secondary stroke prevention. Standard dosage of 1 to $5 \mathrm{mg} / \mathrm{kg} /$ day for a minimum of 3 to 5 years from the acute event is recommended as secondary prevention [50]. The increased risk of Reye's syndrome should be considered. Clopidogrel has been used at dosages of about $1 \mathrm{mg} / \mathrm{kg}$ per day in children unable to take aspirin $[42,51]$.

Thrombolysis with tissue plasminogen activator (tPA) is not currently used and the Royal College of Physicians, AHA Stroke Council, and ACCP guidelines do not recommend it. In fact, the diagnosis of stroke in children is usually made after the time interval required for intravenous or intraarterial tPA thrombolysis ( 3 hours and 6 hours after stroke onset, resp.) [3, 52-54].

The International Paediatric Stroke Study group recommends that thrombolysis should not be used unless it is part of randomised control trial $[55,56]$.

\section{Hemorrhagic Stroke}

Hemorrhagic stroke is as common as arterial ischemic stroke with an estimated incidence of 1.5-2.9 per 100.000 children per year [41]. It includes spontaneous intraparenchymal hemorrhage and nontraumatic subarachnoid hemorrhage.

Structural lesions are the most common causes of intraparenchymal hemorrhages in a population-based cohort [57]. Brain tumors (27\%) and arteriovenous malformations $(17 \%)$ are the most frequent. Medical etiologies are less common. Coagulopathies (13\%) include various causes of thrombocytopenia, hemophilia and von Willebrand's disease, sickle cell anemia (6\%), hypertension (10\%), and infections (6\%). Intraparenchymal hemorrhages of idiopathic origin are also frequent $(23 \%)$.

Non-traumatic subarachnoid hemorrhages are most often caused by intracranial aneurysms. Ruptured aneurysms account for $10 \%$ of intracranial hemorrhages in children. The incidence of subarachnoid hemorrhage is increased in various congenital and hereditary conditions such as cerebral artero-venous malformations, cardiac disorders (coarctation of the aorta, bacterial endocarditis, and atrial myxoma), autosomal dominant polycystic kidney disease, connective tissue abnormalities (Marfan's syndrome, fibromuscular dysplasia, and Ehlers-Danlos type IV), hematological disorders (sickle cell disease, G6PD deficiency, and thalassemia), phakomatoses (neurofibromatosis type 1, especially following radiation therapy and tuberous sclerosis) [58].

Headache or vomiting due to raised intracranial pressure, seizures and focal neurologic deficits are the presenting symptoms in children [41]. During evaluation of pediatric 
TABLE 3: Risk factors for stroke in sickle cell disease.

(i) high blood flow velocity on transcranial Doppler

(ii) low hemoglobin value

(iii) high HbS level

(iv) high white cell and platelet counts

(v) hypertension

(vi) silent brain infarction

(vii) history of chest crisis, transient ischemic attacks, meningitis, seizures, surgery, priapism, acute anemia, and transfusion within 2 weeks before the stroke

stroke it is mandatory to exclude an acute intraparenchymal bleeding. To this end non-contrast TC should be performed.

Treatment of hemorrhagic stroke requires a multidisciplinary team management with neurological and neurosurgical care.

Management options in hemorrhagic stroke fall into two categories: general efforts to stabilize the patient and measures to reduce the risk of rebleeding [5].

Surgical management is controversial, and there is no evidence that surgical evacuation of a supratentorial intraparenchymal hematoma is beneficial at any age $[59,60]$. However, evacuation of a rapidly expanding hematoma causing cerebral herniation may be of benefit [6]. Surgical or endovascular obliteration of aneurysms and arterovenous malformations is effective for many individuals, but stereotactic radiotherapy is being used increasingly in children with artero-venous malformations that are small or difficult to approach surgically. Several large retrospective studies have shown that stereotactic radiotherapy is safe and effective for the treatment of children with an artero-venous malformation $[61,62]$.

Treatment of coagulation defects and hematologic disorders should reduce the risk of subsequent hemorrhage. Emergency splenectomy is indicated for intraparenchymal bleeding associated with idiopathic thrombocytopenic purpura. Other important complications of non-traumatic subarachnoid hemorrhage that require treatment are hydrocephalus, vasospasm, and hyponatremia [5].

\section{Stroke in Sickle Cell Disease}

The most common hematologic risk factor for stroke is sickle cell disease (SCD). Eight percent of patients younger than 19 years will develop a stroke. In this group the highest rate of first ischemic stroke is in children between 2 and 5 years of age while hemorrhagic stroke affects adults aged 20 to 30 years. Both familial and environmental factors seem to be involved in the occurrence of stroke [19]. In the absence of therapy recurrence of stroke is as high as $40 \%$ [63].

Small infarctions have been found on MR in 20 to $35 \%$ of children with SCD in the absence of symptoms [64, 65]. These so-called "silent infarcts," predominantly located in frontal and parietal cortical, subcortical, and border-zone areas are associated with deterioration in cognitive function and with an increased risk of clinically symptomatic stroke $[66,67]$.
Stroke may also be due to large vessel vasculopathy that generally involves the middle cerebral artery territory. Some individuals develop progressive vasculopathy of the intracranial internal carotid artery and of its distal collateral vessels, a picture called moyamoya syndrome. Small infarctions typically involve the basal ganglia and the deep white matter within the anterior circulation.

Risk factors for stroke in SCD are summarized in Table 3.

5.1. Prevention. The presence of high cerebral blood flow velocity as measured by transcranial Doppler (TD) identifies patients at high risk of primary prevention.

In healthy children, the velocity in the middle cerebral artery is around $90 \mathrm{~cm} / \mathrm{s}$ while in SCD children it is 130$140 \mathrm{~cm} / \mathrm{s}$. Stroke risk is high when velocity is $>200 \mathrm{~cm} / \mathrm{s}$.

A randomized trial (Stroke Prevention Trial in Sickle Cell Anemia: STOP) compared periodic blood transfusion with standard care in 130 children with SCD who were selected for high stroke risk on the basis of TD results. The trial was halted because of the high number of strokes in the standardcare arm compared with the transfusion-treated group (11 versus 1), in whom the risk of stroke was reduced from $10 \%$ to $<1 \%$ per year [68].

The current National Heart, Lung, and Blood Institute of the National Institutes of Health (NHLBI) recommendation is to evaluate children between 2 and 16 years with SCD using TD at 6 month intervals. If velocity is $>200 \mathrm{~cm} / \mathrm{s}$, confirmed after a control performed few weeks later, chronic transfusion therapy should be started [63] and should not be discontinued even if TD normalizes (as demonstrated by the randomized controlled trial STOP II [5]).

5.2. Therapy. The treatment of acute ischemic infarction resulting from SCD includes intravenous hydration and exchange transfusion to keep $\mathrm{HbS}<30 \%$ and $\mathrm{Hb}$ between 10-12.5 g/dL [69]. Exchange transfusion avoids the theoretical risk of increasing blood viscosity that could accompany a rapid increase of the hematocrit [5].

\section{Conclusions}

Stroke is relatively rare in children, except, as mentioned, in sickle cell disease. It represents, however, one of the ten "top causes" of childhood death. Its relatively rarity causes a lack of awareness that cerebrovascular disease occurs in children. Furthermore, risk factors and clinical presentation are distinctive compared to adults. For these reasons diagnosis is often delayed. It has been estimated that 48-72 hours frequently elapse between the onset of symptoms and diagnosis [70].

When evaluating a child with stroke, several tests, including imaging studies, are helpful to confirm the diagnosis, to differentiate hemorrhagic from ischemic stroke, and to guide the emergency management.

No uniform approach exists for the treatment of childhood stroke. Until data based on randomized pediatric clinical trials will be available, treatment recommendations for the acute care of children with stroke will continue to be extrapolated from adult guidelines. 


\section{References}

[1] K. Aho, P. Harmsen, and S. Hatano, "Cerebrovascular disease in the community: results of a WHO collaborative study," Bulletin of the World Health Organization, vol. 58, no. 1, pp. 113-130, 1980.

[2] Group TPSW, Ed., Stroke in Childhood. Clinical Guidelines for Diagnosis, Management and Rehabilitation, The Lavenham Press, Suffolk, UK, 2004.

[3] J. V. Hunter, "New radiographic techniques to evaluate cerebrovascular disorders in children," Seminars in Pediatric Neurology, vol. 7, no. 4, pp. 261-277, 2000.

[4] G. W. Albers, L. R. Caplan, J. D. Easton et al., "Transient ischemic attack - proposal for a new definition," New England Journal of Medicine, vol. 347, no. 21, pp. 1713-1716, 2002.

[5] E. S. Roach, M. R. Golomb, R. Adams et al., "Management of stroke in infants and children: a scientific statement from a special writing group of the american heart association stroke council and the council on cardiovascular disease in the young," Stroke, vol. 39, no. 9, pp. 2644-2691, 2008.

[6] G. R. Fleisher and S. Ludwig, Textbook of Pediatric Emergency Medicine, Wolters Kluwer/Lippincott Williams \& Wilkins Health, Philadelphia, Pa, USA, 6th edition, 2010.

[7] V. Ganesan, A. Hogan, N. Shack, A. Gordon, E. Isaacs, and F. J. Kirkham, "Outcome after ischaemic stroke in childhood," Developmental Medicine and Child Neurology, vol. 42, no. 7, pp. 455-461, 2000.

[8] M. Giroud, M. Lemesle, J. B. Gouyon, J. L. Nivelon, C. Milan, and R. Dumas, "Cerebrovascular disease in children under 16 years of age in the city of Dijon, France: a study of incidence and clinical features from 1985 to 1993," Clinical Epidemiology, vol. 48, no. 11, pp. 1343-1348, 1995.

[9] M. J. Lanska, D. J. Lanska, S. J. Horwitz, and D. M. Aram, "Presentation, clinical course, and outcome of childhood stroke," Pediatric Neurology, vol. 7, no. 5, pp. 333-341, 1991.

[10] H. J. Fullerton, Y. W. Wu, S. Sidney, and S. C. Johnston, "Risk of recurrent childhood arterial ischemic stroke in a population-based cohort: the importance of cerebrovascular imaging," Pediatrics, vol. 119, no. 3, pp. 495-501, 2007.

[11] V. Ganesan, M. Prengler, A. Wade, and F. J. Kirkham, "Clinical and radiological recurrence after childhood arterial ischemic stroke," Circulation, vol. 114, no. 20, pp. 2170-2177, 2006.

[12] J. Pappachan and F. J. Kirkham, "Cerebrovascular disease and stroke," Archives of Disease in Childhood, vol. 93, no. 10, pp. 890-898, 2008.

[13] V. Ganesan, M. Prengler, M. A. McShane, A. M. Wade, and F. J. Kirkham, "Investigation of risk factors in children with arterial ischemic stroke," Annals of Neurology, vol. 53, no. 2, pp. 167173, 2003.

[14] G. DeVeber, "Risk factors for childhood stroke: little folks have different strokes!," Annals of Neurology, vol. 53, no. 2, pp. 149150, 2003.

[15] E. Miravet, N. Danchaivijitr, H. Basu, D. E. Saunders, and V. Ganesan, "Clinical and radiological features of childhood cerebral infarction following varicella zoster virus infection," Developmental Medicine and Child Neurology, vol. 49, no. 6, pp. 417-422, 2007.

[16] G. DeVeber, E. Steve Roach, A. R. Riela, and M. Wiznitzer, "Stroke in children: recognition, treatment, and future directions," Seminars in Pediatric Neurology, vol. 7, no. 4, pp. 309$317,2000$.

[17] S. Ciccone, R. Faggioli, F. Calzolari, S. Sartori, M. Calderone, and C. Borgna-Pignatti, "Stroke after varicella-zoster infec- tion: report of a case and review of the literature," Pediatric Infectious Disease Journal, vol. 29, no. 9, pp. 864-867, 2010.

[18] F. J. Kirkham, M. Prengler, D. K. M. Hewes, and V. Ganesan, "Risk factors for arterial ischemic stroke in children," Journal of Child Neurology, vol. 15, no. 5, pp. 299-307, 2000.

[19] M. Lopez-Vicente, S. Ortega-Gutierrez, C. Amlie-Lefond, and M. T. Torbey, "Diagnosis and management of pediatric arterial ischemic stroke," Stroke and Cerebrovascular Diseases, vol. 19, no. 3, pp. 175-183, 2010.

[20] J. K. Lynch, "Cerebrovascular disorders in children," Current Neurology and Neuroscience Reports, vol. 4, no. 2, pp. 129-138, 2004.

[21] H. J. Fullerton, S. C. Johnston, and W. S. Smith, "Arterial dissection and stroke in children," Neurology, vol. 57, no. 7, pp. 1155-1160, 2001.

[22] L. V. Gabis, R. Yangala, and N. J. Lenn, "Time lag to diagnosis of stroke in children," Pediatrics, vol. 110, no. 5, pp. 924-928, 2002.

[23] R. A. Shellhaas, S. E. Smith, E. O’Tool, D. J. Licht, and R. N. Ichord, "Mimics of childhood stroke: characteristics of a prospective cohort," Pediatrics, vol. 118, no. 2, pp. 704-709, 2006.

[24] G. DeVeber, "Stroke and the child's brain: an overview of epidemiology, syndromes and risk factors," Current Opinion in Neurology, vol. 15, no. 2, pp. 133-138, 2002.

[25] D. G. Gadian, F. Calamante, F. J. Kirkham et al., "Diffusion and perfusion magnetic resonance imaging in childhood stroke," Child Neurology, vol. 15, no. 5, pp. 279-283, 2000.

[26] B. P. Jones, V. Ganesan, D. E. Saunders, and W. KlingChong, "Imaging in childhood arterial ischaemic stroke," Neuroradiology, vol. 52, no. 6, pp. 577-589, 2010.

[27] J. L. Sunshine, N. Bambakidis, R. W. Tarr et al., "Benefits of perfusion MR imaging relative to diffusion MR imaging in the diagnosis and treatment of hyperacute stroke," American Journal of Neuroradiology, vol. 22, no. 5, pp. 915-921, 2001.

[28] J. D. Eastwood, M. H. Lev, M. Wintermark et al., "Correlation of early dynamic CT perfusion imaging with whole-brain MR diffusion and perfusion imaging in acute hemispheric stroke," American Journal of Neuroradiology, vol. 24, no. 9, pp. 18691875, 2003.

[29] U. Nowak-Göttl, G. Günther, K. Kurnik, R. Sträter, and F. Kirkham, "Arterial ischemic stroke in neonates, infants, and children: an overview of underlying conditions, imaging methods, and treatment modalities," Seminars in Thrombosis and Hemostasis, vol. 29, no. 4, pp. 405-414, 2003.

[30] B. Husson, G. Rodesch, P. Lasjaunias, M. Tardieu, and G. Sébire, "Magnetic resonance angiography in childhood arterial brain infarcts: a comparative study with contrast angiography," Stroke, vol. 33, no. 5, pp. 1280-1285, 2002.

[31] V. Ganesan, L. Savvy, W. K. Chong, and F. J. Kirkham, "Conventional cerebral angiography in children with ischemic stroke," Pediatric Neurology, vol. 20, no. 1, pp. 38-42, 1999.

[32] B. Husson and P. Lasjaunias, "Radiological approach to disorders of arterial brain vessels associated with childhood arterial stroke- a comparison between MRA and contrast angiography," Pediatric Radiology, vol. 34, no. 1, pp. 10-15, 2004.

[33] K. Calder, P. Kokorowski, T. Tran, and S. Henderson, "Emergency department presentation of pediatric stroke," Pediatric Emergency Care, vol. 19, no. 5, pp. 320-328, 2003.

[34] E. Mekitarian Filho and W. B. De Carvalho, "Stroke in children," Jornal de Pediatria, vol. 85, no. 6, pp. 469-479, 2009.

[35] U. Nowak-Göttl, R. Sträter, A. Heinecke et al., "Lipoprotein (a) and genetic polymorphisms of clotting factor V, prothrombin, 
and methylenetetrahydrofolate reductase are risk factors of spontaneous ischemic stroke in childhood," Blood, vol. 94, no. 11, pp. 3678-3682, 1999.

[36] G. Kenet, S. Sadetzki, H. Murad et al., "Factor V Leiden and antiphospholipid antibodies are significant risk factors for ischemic stroke in children," Stroke, vol. 31, no. 6, pp. 1283$1288,2000$.

[37] E. Nestoridi, F. S. Buonanno, R. M. Jones et al., "Arterial ischemic stroke in childhood: the role of plasma-phase risk factors," Current Opinion in Neurology, vol. 15, no. 2, pp. 139$144,2002$.

[38] D. L. Atkins, M. D. Berg, R. A. Berg et al., "Pediatric basic and advanced life support," Pediatrics, vol. 117, no. 5, pp. e955e977, 2006.

[39] K. Becker, "Intensive care unit management of the stroke patient," Neurologic Clinics, vol. 18, no. 2, pp. 439-454, 2000.

[40] F. J. Kirkham, "Is there a genetic basis for pediatric stroke?" Current Opinion in Pediatrics, vol. 15, no. 6, pp. 547-558, 2003.

[41] M. T. Mackay and A. Gordon, "Stroke in children," Australian Family Physician, vol. 36, no. 11, pp. 896-902, 2007.

[42] L. C. Jordan, "Assessment and treatment of stroke in children," Current Treatment Options in Neurology, vol. 10, no. 6, pp. 399-409, 2008.

[43] J. Sahuquillo and F. Arikan, "Decompressive craniectomy for the treatment of refractory high intracranial pressure in traumatic brain injury," Cochrane Database of Systematic Reviews, no. 1, Article ID CD003983, 2006.

[44] G. A. deVeber, "Cerebrovascular disease," in Pediatric Neurology Principles \& Practice, K. F. Swaiman, S. Ashwal, and D. Ferriero, Eds., vol. 2, pp. 1759-1802, Mosby-Elsevier, 4th edition, 2006.

[45] "Recognition and treatment of stroke in children," http://www .ninds.nih.gov/news_and_events/proceedings/stroke_proceedings/childneurology.htm.

[46] P. Massicotte, M. Adams, V. Marzinotto, L. A. Brooker, and M. Andrew, "Low-molecular-weight heparin in pediatric patients with thrombotic disease: a dose finding study," Journal of Pediatrics, vol. 128, no. 3, pp. 313-318, 1996.

[47] C. R. Burak, M. D. Bowen, and T. F. Barron, "The use of enoxaparin in children with acute, nonhemorrhagic ischemic stroke," Pediatric Neurology, vol. 29, no. 4, pp. 295-298, 2003.

[48] R. Sträter, K. Kurnik, C. Heller, R. Schobess, P. Luigs, and U. Nowak-Göttl, "Aspirin versus low-dose low-molecular-weight heparin: antithrombotic therapy in pediatric ischemic stroke patients: a prospective follow-up study," Stroke, vol. 32, no. 11, pp. 2554-2558, 2001.

[49] D. Dix, M. Andrew, V. Marzinotto et al., "The use of low molecular weight heparin in pediatric patients: a prospective cohort study," Pediatrics, vol. 136, no. 4, pp. 439-445, 2000.

[50] P. Monagle, A. Chan, P. Massicotte, E. Chalmers, and A. D. Michelson, "Antithrombotic therapy in children: the seventh ACCP Conference on Antithrombotic and Thrombolytic Therapy," Chest, vol. 126, no. 3, pp. 645S-687S, 2004.

[51] T. Soman, M. F. Rafay, S. Hune, A. Allen, D. MacGregor, and G. DeVeber, "The risks and safety of clopidogrel in pediatric arterial ischemic stroke," Stroke, vol. 37, no. 4, pp. 1120-1122, 2006.

[52] A. Gruber, C. Nasel, W. Lang, E. Kitzmüller, G. Bavinzski, and T. Czech, "Intra-arterial thrombolysis for the treatment of perioperative childhood cardioembolic stroke," Neurology, vol. 54, no. 8, pp. 1684-1686, 2000.

[53] S. S. Thirumalai and R. A. Shubin, "Successful treatment for stroke in a child using recombinant tissue plasminogen activator," Journal of Child Neurology, vol. 15, no. 8, p. 558, 2000.

[54] W. Zenz, F. Arlt, S. Sodia, and A. Berghold, "Intracerebral hemorrhage during fibrinolytic therapy in children: a review of the literature of the last thirty years," Seminars in Thrombosis and Hemostasis, vol. 23, no. 3, pp. 321-332, 1997.

[55] D. Eleftheriou and V. Ganesan, "Treatment strategies for childhood stroke," Expert Opinion on Pharmacotherapy, vol. 9, no. 17, pp. 2955-2967, 2008.

[56] C. Amlie-Lefond, G. deVeber, A. K. Chan et al., "Use of alteplase in childhood arterial ischaemic stroke: a multicentre, observational, cohort study," The Lancet Neurology, vol. 8, no. 6, pp. 530-536, 2009.

[57] L. C. Jordan, J. T. Kleinman, and A. E. Hillis, "Intracerebral hemorrhage volume predicts poor neurologic outcome in children," Stroke, vol. 40, no. 5, pp. 1666-1671, 2009.

[58] J. Punt, "Surgical management of paediatric stroke," Pediatric Radiology, vol. 34, no. 1, pp. 16-23, 2004.

[59] H. H. Batjer, J. S. Reisch, B. C. Allen, L. J. Plaizier, and C. Jen $\mathrm{Su}$, "Failure of surgery to improve outcome in hypertensive putaminal hemorrhage. A prospective randomized trial," Archives of Neurology, vol. 47, no. 10, pp. 1103-1106, 1990.

[60] S. H. Tan, P. Y. Ng, T. T. Yeo, S. H. Wong, P. L. Ong, and N. Venketasubramanian, "Hypertensive basal ganglia hemorrhage: a prospective study comparing surgical and nonsurgical management," Surgical Neurology, vol. 56, no. 5, pp. 287-292, 2001.

[61] M. Shin, S. Kawamoto, H. Kurita et al., "Retrospective analysis of a 10-year experience of stereotactic radio surgery for arteriovenous malformations in children and adolescents," Neurosurgery, vol. 97, no. 4, pp. 779-784, 2002.

[62] A. A. Cohen-Gadol and B. E. Pollock, "Radiosurgery for arteriovenous malformations in children," Journal of Neurosurgery, vol. 104, no. 6, pp. 388-391, 2006.

[63] D. Bulas, "Screening children for sickle cell vasculopathy: guidelines for transcranial doppler evaluation," Pediatric Radiology, vol. 35, no. 3, pp. 235-241, 2005.

[64] J. L. Kwiatkowski, R. A. Zimmerman, A. N. Pollock et al., "Silent infarcts in young children with sickle cell disease," British Journal of Haematology, vol. 146, no. 3, pp. 300-305, 2009.

[65] R. G. Steen, T. Emudianughe, G. M. Hankins et al., "Brain imaging findings in pediatric patients with sickle cell disease," Radiology, vol. 228, no. 1, pp. 216-225, 2003.

[66] F. D. Armstrong, R. J. Thompson Jr., W. Wang et al., "Cognitive functioning and brain magnetic resonance imaging in children with sickle cell disease. neuropsychology committee of the cooperative study of sickle cell disease," Pediatrics, vol. 97, no. 6, pp. 864-870, 1996.

[67] S. T. Miller, E. A. Macklin, C. H. Pegelow et al., "Silent infarction as a risk factor for overt stroke in children with sickle cell anemia: a report from the cooperative study of sickle cell disease," Journal of Pediatrics, vol. 139, no. 3, pp. 385-390, 2001.

[68] H. J. Fullerton, R. J. Adams, S. Zhao, and S. C. Johnston, "Declining stroke rates in californian children with sickle cell disease," Blood, vol. 104, no. 2, pp. 336-339, 2004.

[69] R. J. Adams, K. Ohene-Frempong, and W. Wang, "Sickle cell and the brain," Hematology / American Society of Hematology. Education Program, pp. 31-46, 2001.

[70] S. Kuhle, L. Mitchell, M. Andrew et al., "Urgent clinical challenges in children with ischemic stroke: analysis of 1065 patients from the 1-800-NOCLOTS pediatric stroke telephone consultation service," Stroke, vol. 37, no. 1, pp. 116-122, 2006. 


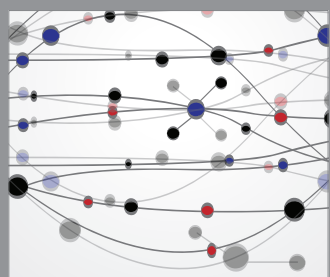

The Scientific World Journal
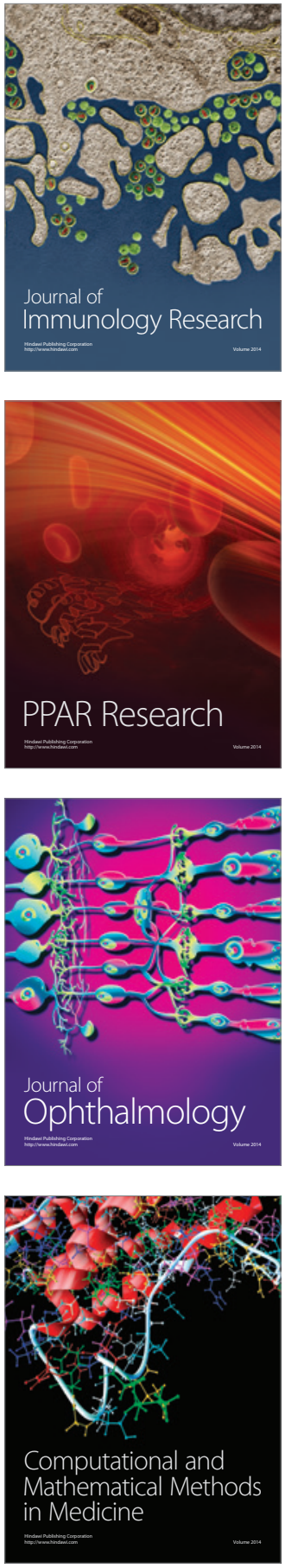

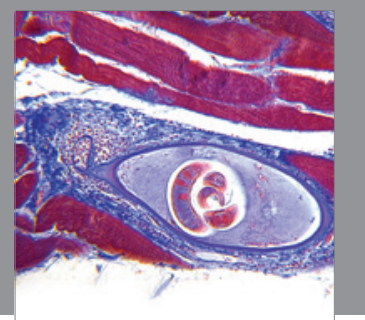

Gastroenterology

Research and Practice
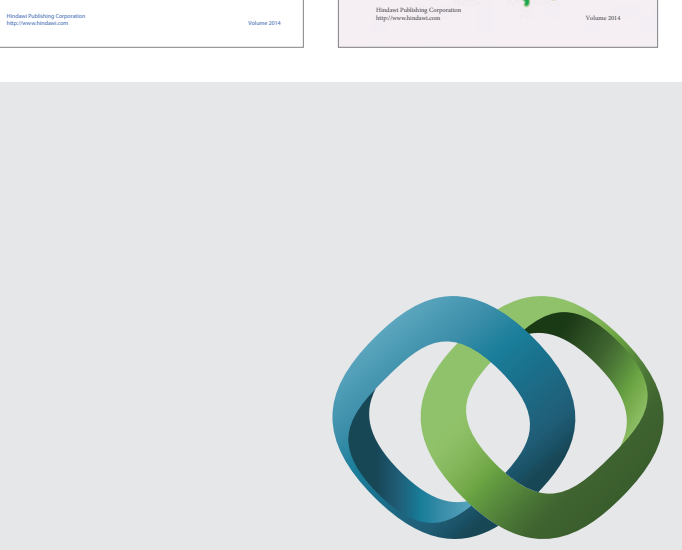

\section{Hindawi}

Submit your manuscripts at

http://www.hindawi.com
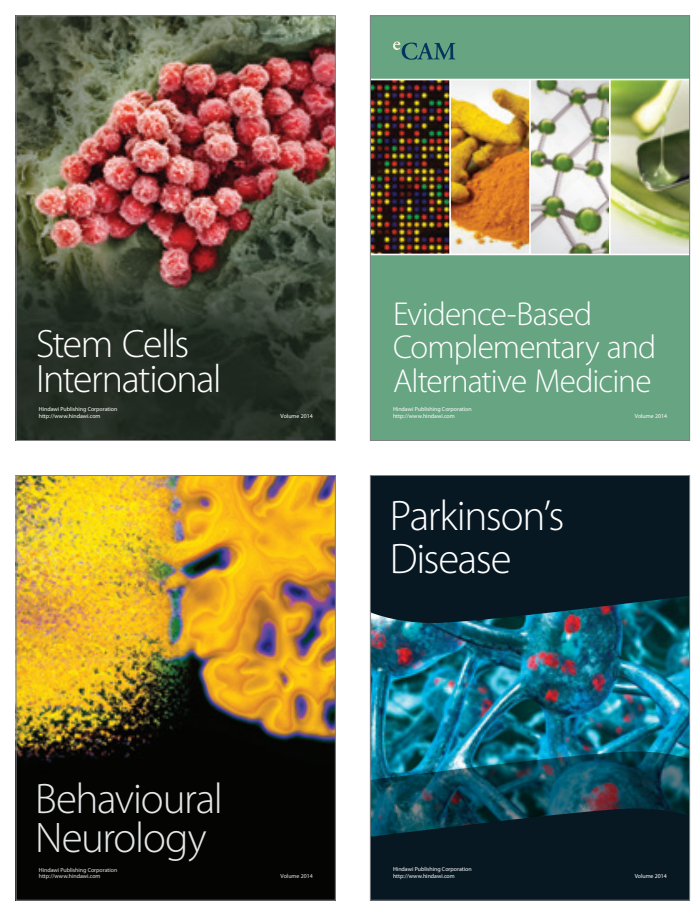

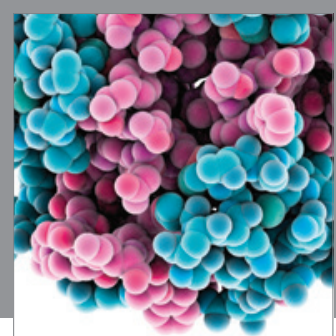

Journal of
Diabetes Research

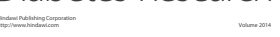

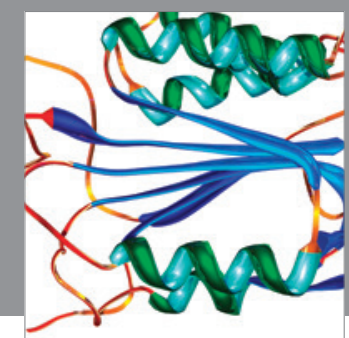

Disease Markers
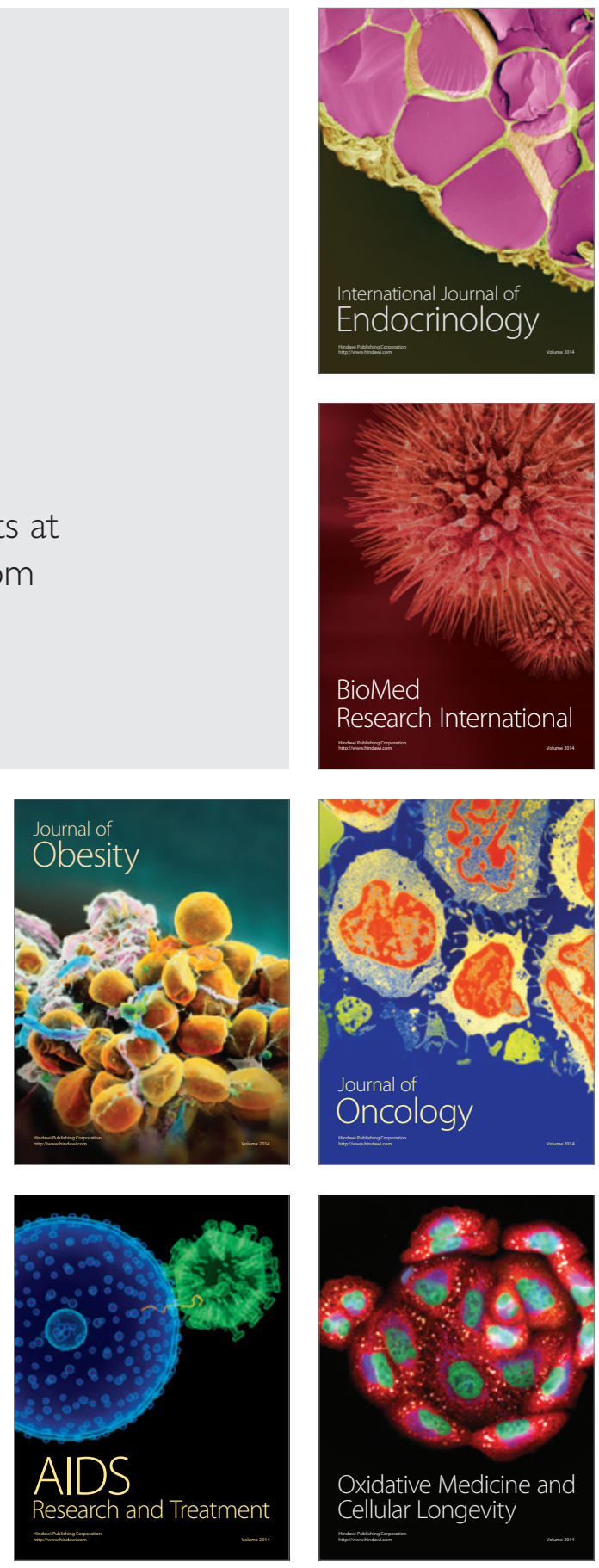